\title{
Women's victimisation and safety in transit environments
}

\author{
Vania Ceccato ${ }^{1}$
}

(C) Macmillan Publishers Ltd 2017

\begin{abstract}
Sexual harassment and other forms of sexual violence in public spaces are an everyday occurrence for women and girls around the world....It happens on streets, in and around public transportation, schools and workplaces, in public sanitation facilities, parks.... This reality reduces women's and girls' freedom of movement. It reduces their ability to participate in school, work and public life. Although violence in the private domain is now widely recognized as a human rights violation, violence against women and girls, especially sexual harassment in public spaces, remains a largely neglected issue (UN Women 2017).
\end{abstract}

This special issue brings together eight articles that characterise women's victimisation and safety in transit environments. Why a special issue devoted to women's transit safety? Victimisation in transit environments is gendered (Ceccato 2013; Loukaitou-Sideris 2004; Peters 2013; Smith 2008). Although men are more often crime victims on public transport than are women (Morgan and Smith 2006), women declare being more fearful than men (Ceccato 2013; Dymén and Ceccato 2012; Loukaitou-Sideris 2015, 2016). Differences between male and female victimisation patterns are important because they may help crime prevention specialists determine the types of measures that are most appropriate for preventing particular crimes (Smith 2008).

Apart from the concerns of victimisation and perceived safety, there are other important reasons of why one should look closely at women's safety while in transit. First, women use public transport more than men. In the USA, for example, $64 \%$ of the people riding Philadelphia's subways and buses are women, 62\% in Chicago's

Vania Ceccato

vania.ceccato@abe.kth.se

$1 \quad$ Stockholm, Sweden 
MTA and 60\% in Washington, D.C., New York, and Boston (Goodyear 2015). In Sweden, previous research has shown that women are less likely to have access to a car (Lundkvist 1998, p. 39) and tend to take more, shorter and more varied trips (trip chains) at more varied times (although they tend to travel less at night) (Kunieda and Gauthier 2007, p. 6), which imposes specific needs for transportation but also for the way cities are planned (Dymén and Ceccato 2012).

Research has also found that, in some cities, especially those in the Global South, a large percentage of women are 'transit captives', namely they have relatively less access to non-public forms of transportation and are therefore overly reliant on public transport. If public transportation is not reliable or safe (or at least, perceived to be), mobility is impaired. Women may create strategies to address the risk of being a victim of crime by avoiding certain routes, neutralising feelings of insecurity (Junger 1987), rescheduling the trip or bringing a companion (Keane 1998). They constitute millions of passengers all around the world. Moreover, bus drivers and train conductors across the world are predominantly male. This male bias 'typically extends from the operational into the managerial and executive levels at transit agencies' (Peters 2013, 10). Thus, there is an urgent need to draw attention to issues of women's victimisation and other passengers' safety needs in public transportation research and policy.

The intersectionality of women's safety (age, economic status, ethnicity but also differences in physical and cognitive abilities, see, e.g. Sokoloff and Dupont 2005), is an essential element of the articles presented in this special issue. In other words, fear and victimisation are not only about age or gender but rather a result of the intersection of a set of individual's characteristics. Being a disabled and poor individual creates 'synergic layers of disadvantage' that affect how one perceives and experiences the world and expresses fear. Previous research has shown that information is a decisive factor in vulnerable users' decisions to travel, especially to unfamiliar destinations (Iudici 2015; Sochor 2015).

An important achievement with this special issue is that although articles often focus on safety in particular transit environments (at stations, on buses, on carriages), some of them have made an attempt to approach safety adopting 'a whole journey perspective' (Loukaitou-Sideris 2004; Smith 2008; Yu and Smith 2014). This means that their analytical focus has been safety along the journey and/ or across public spaces, which imposes a number of challenges not only analytically in research but also in terms of tackling problems in practice. Ceccato (2013) suggests that implementing a whole journey approach requires cooperation between the stakeholders responsible for the delivery of transportation services and security providers, the police, municipalities and planners, NGOs, and private citizens, women in particular. In practice, this approach demands more than 'quick fixes' to the physical environment and has to overcome barriers that lead to poor cooperation between stakeholders in ensuring transit safety.

This special issue offers a strong international outlook by combining empirical research drawing from case studies from Brazil, France, India, Italy, the UK and the USA written by individual scholars or teams of researchers based in these countries. Moreover, the contributions of this special issue are characterised by high-quality applied research that relies on environmental criminology theories and principles of 
situational crime prevention, while being open to a multidisciplinary perspective. We believe that a special issue like this appeals to a wide scientific community including academic researchers, experts from government agencies, policy and decisionmakers working with transit safety, and professionals and practitioners working with gender and issues of intersectionality in the context of safety in transit environments.

\section{Framing the articles of the special issue}

The special issue is composed of two parts, each with four articles. The first part starts with an article by Mangai Natarajan and colleagues, Sexual victimization of college students in public transport environments: A whole journey approach, which addresses young women's experiences of sexual victimisation during the commute to college. The analysis is informed by a 'whole journey' approach that includes walking to and from bus/subway stops as well as waiting for and riding the bus or subway in New York, USA. Although a small-scale study, the analysis indicates extensive patterns of victimisation during all stages of the trip to college. Also focusing on safety along the trip, Hugo d' Arbois de Jubainville and Camille Vanier assess whether and how female passengers change their routines when feeling unsafe in the transit environment in the Parisian region. The study, Women's avoidance behaviour in public transport in the Ile-de-France region, relies on data from the French victimisation survey and constitutes one of the few articles of this special issue that is based on a large-sample data set. Their findings suggest that women's education, previous victimisation and declared perceived safety are consistently associated with time-based and space-based avoidance behaviour in transit environments.

The role of bystanders in cases of events of unwanted sexual behaviour was assessed in the article by Krista Ball and Caroline Wesson called Bystanders' perceptions of unwanted sexual behaviour on public transport: Exploring transport density and behaviour severity. The study is based on a self-selecting, relatively small sample from a university in the UK. The novelty with this study is that the methodology combines a series of vignettes (that manipulated passenger density and severity of the behaviour) and a video to focus on bystanders' perceptions and expected responses to unwanted sexual behaviours on public transport. Findings indicated that the blame was attributed to the perpetrator (and not the victim) and that incident seriousness and likelihood of reporting an event were both influenced by, for instance, passenger density in a transit setting.

Also elsewhere, high-density environments (in particular, overcrowded carriages) are a facilitator of crimes against female passengers - a condition that also triggers bystanders' interventions. Vania Ceccato and Yuri Paz report on the overall safety conditions in the metro in São Paulo, the largest rapid transit system in Brazil, and the second largest in South America. The study is entitled Crime in São Paulo's metro system: Focus on sexual crimes against women. The analysis combines crime records with data collected using Google street view and other secondary data using geographical information system (GIS). Although sexual violence is highly underreported, current data indicate concentrations in space and time (the busiest central stations, often during morning and afternoon rush hours). The study finalises 
by reflecting upon current crime intervention programmes directed at women's sexual victimisation in the metro system and making suggestions for future improvement engaging women in the process.

The second part of this special issue includes two case studies from India. The first article makes use of crowdsourced data to investigate the nature of women's self-reports of harassment and assault on public buses. The article is written by Suzanne Lea, Abhijith Asok and Elsa da Silva, one of the founders of the Safecity.in initiative, a platform that crowdsources personal stories of sexual harassment and abuse in public spaces. The article is entitled Women's strategies addressing sexual harassment and assault on public buses: An analysis of crowdsourced data and is based on a relatively small sample data set. On top of asserting crowdmapping as a multifaceted tool, the study also suggests that women's strategy of confronting incidents by 'making a scene' and 'engaging the crowd' plays in their favour in the closed, shared-space setting, such as crowded buses.

The second article is also based in India and written by Kartikeya Tripathi, Hervé Borrion and Jyoti Belur. Sexual harassment of students on public transport: An exploratory study in Lucknow, India, explores actual and witnessed victimisation as well as risk perceptions of a sample of female students. Findings show that sexual harassment appears to be most prevalent on buses and increases with the frequency of public transport use. More interestingly, they find that the numbers of incidents experienced as a victim and as a witness are comparable, suggesting that events of sexual harassment are not widely noticed by other passengers. The authors conclude the article by discussing potential reasons for this pattern.

The third article by Camille Vanier and Hugo d'Arbois de Jubainville focuses on the types of women who use public transportation and their declared levels of perceived safety. Feeling unsafe in public transportation: A profile analysis of female users in the Parisian region is based on cluster analysis of data from the national victimisation survey (2010-2013). They identify four types of users depending on their individual characteristics and mobility habits.

In a parallel vein, Antonio Iudici, Laura Bertoli and Elena Faccio, in the article The 'invisible' needs of women with disabilities in transportation systems, also focus on female users, but this time, on the safety of those who declare themselves as having a disability. This article offers a review of international literature concerning women's victimisation and safety in transit environments with focus on, among other things, the concept of vulnerability, patterns of victimisation in transport systems and prevention policies and intervention strategies devoted to this particular group of transit users.

I provide a broadly focused 'afterword' entitled Women's transit safety: making connections and defining future directions in research and policy for this special issue. My reflections consider the larger framework and identify directions for both future research and practice.

Acknowledgements I am grateful to all authors who submitted interesting articles to this special issue. In the selection process, I relied heavily on the work (assessment and opinions) gently provided by the referees. Many thanks go to all anonymous referees. I wish to acknowledge the editor-in-chief Professor Rob Mawby who guided me along the way. I would like to thank colleagues, students and friends from the Department of Urban Planning and Environment, School of Architecture and the Built Environment 
(ABE), KTH Royal Institute of Technology, in particular Mackenzie Childs for her support with article formatting. I would like to thank the contributors to the discussions that took place in the userlist TCR_Network (Transit Crime Network) that provided advice to myself and other authors when we were writing our articles. Thanks also to all participants of the session on women's transit safety in the 2016's Conference of American Association of Criminology - ASC in New Orleans, USA. I am pleased to share with you the knowledge gathered in these eight articles and afterword on women's transit safety. Enjoy!

\section{References}

Ceccato, V. 2013. Moving safely: Crime and perceived safety in Stockholm's Subway Stations. Lanham: Lexington.

Dymén, C., and V. Ceccato. 2012. An international perspective of the gender dimension in planning for urban safety. In The urban fabric of crime and fear, ed. V. Ceccato, 311-339. Dordrecht: Springer.

Goodyear, S. 2015. More women ride mass transit than men. Shouldn't transit agencies be catering to them? https://www.citylab.com/transportation/2015/01/more-women-ride-mass-transit-than-menshouldnt-transit-agencies-be-catering-to-them/385012/. Accessed 5 May 2017.

Iudici, A. 2015. Sexual harassment against people with mental disabilities in transit environments: implications for services and clinics. In Safety and security in transit environments, ed. V. Ceccato, and A. Newton, 328-343. Palgrave: Basingstoke.

Junger, M. 1987. Women's experiences of sexual harassments: Some implications for their fear of crime. The British Journal of Criminology 27(4): 358-383.

Keane, C. 1998. Evaluating the influence of fear of crime as an environmental mobility restrictor on women's routine activities. Environment and Behavior 30(1): 60-74.

Kunieda, M., and A. Gauthier. 2007. Gender and urban transport: Fashionable and affordable. Sustainable transport: A sourcebook for policy makers in developing cities. Eschborn: Technische Zusammenarbeit.

Loukaitou-Sideris, A. 2004. Is it safe to walk here? Paper presented at the Conference Proceedings Research on Women's Issues in Transportation: Report of a conference, Chicago, IL, 18-20 November. Washington, DC: Transportation Research Board.

Loukaitou-Sideris, A. 2015. Intimidate riders: US Women's perspectives about safety in transit settings. In Safety and security in transit environments, ed. V. Ceccato, and A. Newton, 291-308. Palgrave: Basingstoke.

Loukaitou-Sideris, A. 2016. A gendered view of mobility and transport: Next steps and future directions. Town Planning Review 87(5): 547-565.

Lundkvist, H. 1998. Ojämställdhetens Miljöer. Stockholm: Svenska kommunförbundet och Kommentus förlag.

Morgan, R., and M.J. Smith. 2006. Crimes against passengers: Theft, robbery, assault and indecent assault. In Secure and tranquil travel: Preventing crime and disorder on public transport, ed. D.B.C.M.J. Smith, 77-102. London: Jill Dando Institute of Crime Science.

Peters, D. 2013. Gender and sustainable urban mobility. Global Report on Human Settlements 2013. https://unhabitat.org/wp-content/uploads/2013/06/GRHS.2013.Thematic.Gender.pdf. Accessed 5 May 2017.

Smith, M.J. 2008. Addressing the security needs of women passengers on public transport. Security Journal 21(1): 117-133.

Sochor, J. 2015. Enhancing mobility and perceived safety via ICT: The case of a navigation system for visually impaired users. In Safety and security in transit environments: An interdisciplinary approach, ed. V. Ceccato, and A. Newton, 344-361. London: Palgrave Macmillan.

Sokoloff, N.J., and I. Dupont. 2005. Domestic violence at the intersections of race, class, and gender. Violence Against Women 11(1): 38-64.

UN Women. 2017. Creating safe public spaces. Safe cities global initiatives. www.unwomen.org. Accessed 19 May 2017.

Yu, S.-S.V., and M.J. Smith. 2014. Commuters using public transit in New York City: Using area-level data to identify neighbourhoods with vulnerable riders. Security Journal 27(2): 194-209. 